\title{
Alkylidene Meldrum's Acids as Platforms for the Vinylogous Synthesis of Dihydropyranones
}

\author{
Stéphane Wittmann, ${ }^{[[a]}$ Thomas Martzel, ${ }^{+[b]}$ Cong Thanh Pham Truong, ${ }^{[a]}$ Martial Toffano, ${ }^{[a]}$ \\ Sylvain Oudeyer, ${ }^{[b]}$ Régis Guillot, ${ }^{[a]}$ Chloée Bournaud,,${ }^{[a]}$ Vincent Gandon, ${ }^{[a, c]}$ Jean-François \\ Brière, ${ }^{*[b]}$ and Giang Vo-Thanh ${ }^{*[a]}$
}

\begin{abstract}
Upon Brønsted base organocatalysis, ketone derived alkylidene Meldrum's acids proved to be competent vinylogous platforms able to undergo a formal (4+2) cycloaddition reaction with dihydro-2,3-furandione to furnish an unprecedented route to 3,6-dihydropyran-2-ones 5 as spiro[4,5]decane derivatives with up to $98 \%$ ee thanks to the commercially available Takemoto catalyst. Preliminary investigation showed that this reaction could be extended to other activated ketones establishing these alkylidene Meldrum's acids as a novel C4-synthon in the vinylogous series.
\end{abstract}

The principle of vinylogy, as remarkably illuminated by Fuson in $1935,{ }^{[1]}$ allows the remote functionalization of a given functional group thanks to the propagation of electronic effects through a conjugated unsaturated backbone (Scheme $1 \mathrm{~A})$. More recently, synthetic chemists have tackled the more challenging regio- and enantioselective bond-forming events at remote positions of various electron-withdrawing groups by means of metal or organic catalysts. ${ }^{[2],[3]}$ This methodology was especially illustrated by the groups of Jørgensen, Deng and Chen during the pioneering organocatalytic direct $\delta$ functionalization of $\alpha, \alpha$-dicyanoolefins platforms. ${ }^{[4]}$ The marked versatility of this vinylogous strategy has witnessed several achievements encompassing the use of various substrates suited for direct organocatalytic activation sequences. ${ }^{[2],[3]}$ Upon the initiatives of Peters and $Y e,{ }^{[5],[6]}$ the catalytic vinylogous transformation of crotonyl-based platforms, such as $\alpha, \beta$ unsaturated acid chlorides, opened an avenue to the elaboration of 5,6-dihydropyran-2-ones 1 (Scheme 1A), a heterocyclic core-structure found in numerous bioactive compounds. ${ }^{[2],[3]}$ By means of chiral $\mathrm{N}$-Heterocyclic Carbenes $(\mathrm{NHC})$ or amines $\left(\mathrm{R}_{3} \mathrm{~N}\right.$, Scheme $\left.1 \mathrm{~A}\right),{ }^{[7],[8]}$ efficient $(4+2)$ annulation reactions were subsequently carried out with ketone derivatives and provided thereby the corresponding oxa-heterocycles 1 with the control of a congested tetrasubstituted stereocenter, even embedded into highly valuable spiro architectures..$^{[9]}$ Nevertheless, to the best of our knowledge, this strategy has exclusively led to 5,6-dihydropyran-2-ones 1 , with a conjugated carbon-carbon double bond to the $\mathrm{C}=\mathrm{O}$ group (via C4 synthon 2). In consequence, the development of novel platforms expanding the scope of this valuable vinylogous methodology is still of high interest.

[a] Dr. S. Wittmann, C. T. Pham Truong, Dr. M. Toffano, Dr. R. Guillot,

Dr. C. Bournaud, Prof. V. Gandon and Prof. G. Vo-Thanh

Institut de Chimie Moléculaire et des Matériaux d'Orsay. CNRS

UMR 8182, Université Paris Saclay

91405 Orsay Cedex, France.

E-mail: giang.vo-thanh@universite-paris-saclay.fr

[b] Dr. T. Martzel, Dr. S. Oudeyer and Dr. J.-F. Brière

Normandie Univ, UNIROUEN, INSA Rouen, CNRS, COBRA, 76000

Rouen, France.

E-mail: jean-francois.briere@insa-rouen.fr

[c] Prof. V. Gandon

Laboratoire de Chimie Moléculaire (LCM), CNRS UMR 9168, Ecole

Polytechnique, Institut Polytechnique de Paris, route de Saclay,

91128 Palaiseau cedex, France

${ }^{[}{ }^{+}$These authors contributed equally to this work

Supporting information for this article is given via a link at the end of the document.((Please delete this text if not appropriate)) 
(A) Enantioselective synthesis of valuable 5,6-dihydropyran-2-ones 1

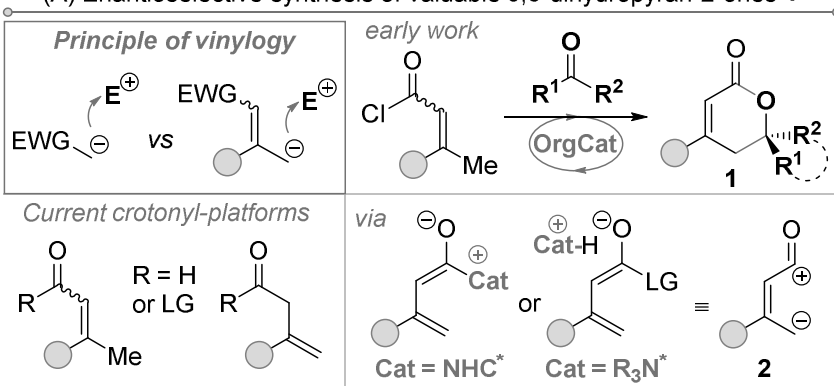

(B) Novel Meldrum's acid based platform $\mathbf{3}$ in vinylogous series (this work)

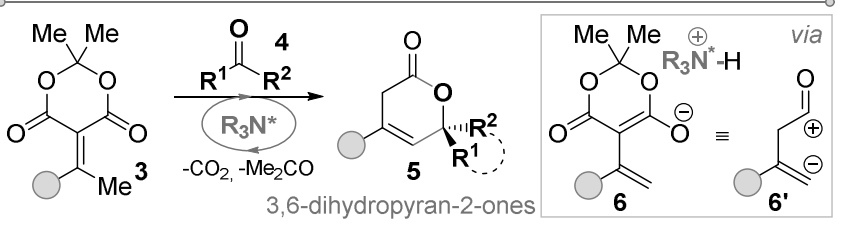

Scheme 1. Novel organocatalytic vinylogous synthesis of dihydropyran-2-ones.

In that vein, we started to investigate the alkylidene Meldrum's acid derivatives 3, as an original platform in vinylogous series (Scheme 1B). These compounds are stable and readily available in one-step by the condensation reaction between Meldrum's acid and ketones. ${ }^{[10]}$ With regard to the remarkable high acidity of the 2,2-dimethyl-1,3-dioxan-4,6-dione, namely Meldrum's acid ( $\mathrm{p} K_{\mathrm{a}}=4.8$ in water) ${ }^{[11]}$ we anticipated a facile deprotonation of the distant methyl group of 3 , so that the formation of the enolate 6 with a $y$-nucleophilic site would occur, ${ }^{[12]}$ following the principle of vinylogy. Then, taking advantage of the marked electrophilic properties of carbonyl moieties of the 1,3-dioxan-4,6-dione backbone, the platform 3 was expected to be capable of undergoing a formal $(4+2)$ cycloaddition with ketones through a domino aldol/cyclocondensation reaction towards the construction of dihydropyran-2-one. We are pleased to report on the alkylidene Meldrum's acid derivatives 3 as a novel precursor in enantioselective vinylogous transformations upon Brønsted base organocatalysis. The exquisite reactivity of platform 3 allows an unprecedented entry to non-racemic 3,6dihydropyran-2-ones 5, having a non-conjugated carbon-carbon double bond (via synthon 6' instead of 2) which, accordingly, extends the chemical space in the dihydropyran-2-one heterocyclic series.

This project began by the exploration of alkylidene Meldrum's acid $\mathbf{3}$ reactivity as a potentially vinylogous platform (Scheme 2). To our delight, the model benzylidene Meldrum's acid 3a and dihydro-4,4-dimethyl-2,3-furandione 4a as electrophile led straightforwardly to the formation of virtually novel spiranic 5,6-dihydropyran-2-ones 1aa in the presence of 20 mol\% of DBU as a base (unoptimized conditions). ${ }^{[13]}$ This smooth domino sequence could be applied to an array of diketones $\mathbf{4 b}$-e to afford the corresponding 5,6-dihydropyran-2-ones 1ab-1ae derivatives as major products in yields ranging from $47 \%$ to $72 \%$.
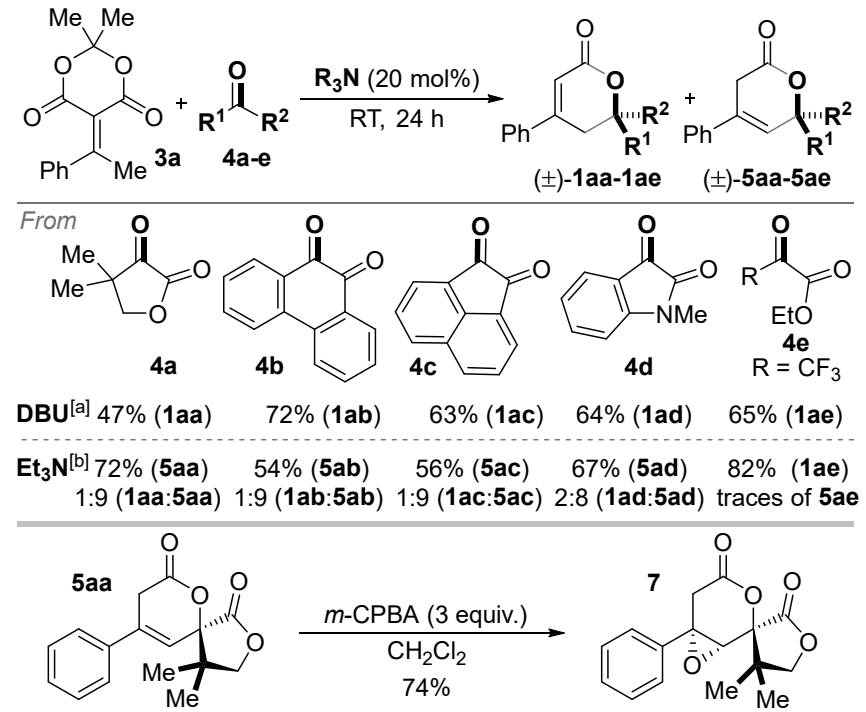
Scheme 2. Alkylidene Meldrum's acid 3a as an original vinylogous platform. Percentage correspond to the isolated yield after column chromatography, and the ratio of isomers (1:5) was determined by ${ }^{1} \mathrm{H}$ NMR on the crude product. [a] In THF (0.2 M); only traces of 5a- was observed. [b] $\ln \mathrm{CH}_{2} \mathrm{Cl}_{2}(0.4 \mathrm{M})$.

Surprisingly, in the course of these processes, we also detected minor amounts of the non-conjugated 3,6-dihydropyran2-ones 5. By means of triethylamine as a softer organocatalyst in dichloromethane, the outcome of the reaction was essentially balanced towards the construction of 3,6-dihydropyran-2-one isomers 5aa-ad with yields ranging from 54-72\%, except for the more reactive keto-ester $4 \mathbf{e}$ giving the known 5,6-dihydropyran-2-ones 1 ae in good $82 \%$ yield. ${ }^{[7 a]}$ The structure of the novel compound 5 aa was fully proven especially by X-Ray single crystal diffraction. ${ }^{[14]}$ Interestingly, the 3,6-dihydropyran-2-one product 5aa isomerized into the conjugated isomer 1 aa in the presence of $\mathrm{Et}_{3} \mathrm{~N}$ for 24 hours. Then, we assume that 1aa (thermodynamic product) is mainly originated from the kinetic product 5aa during this domino sequence, whose outcome depends on both the strength of the base and the stability and/or acidity of the intermediates. Accordingly, alkylidene Meldrum's acid derivative 3a proved to be an original and versatile vinylogous platform, while affording an unprecedented pathway to original 3,6-dihydropyran-2-ones 5. Furthermore, the usefulness of these products was demonstrated through the stereoselective epoxidation reaction which took place regioselectively without C-C double bond migration (7, 74\%). Then, we embarked towards the development of an organocatalytic enantioselective version.

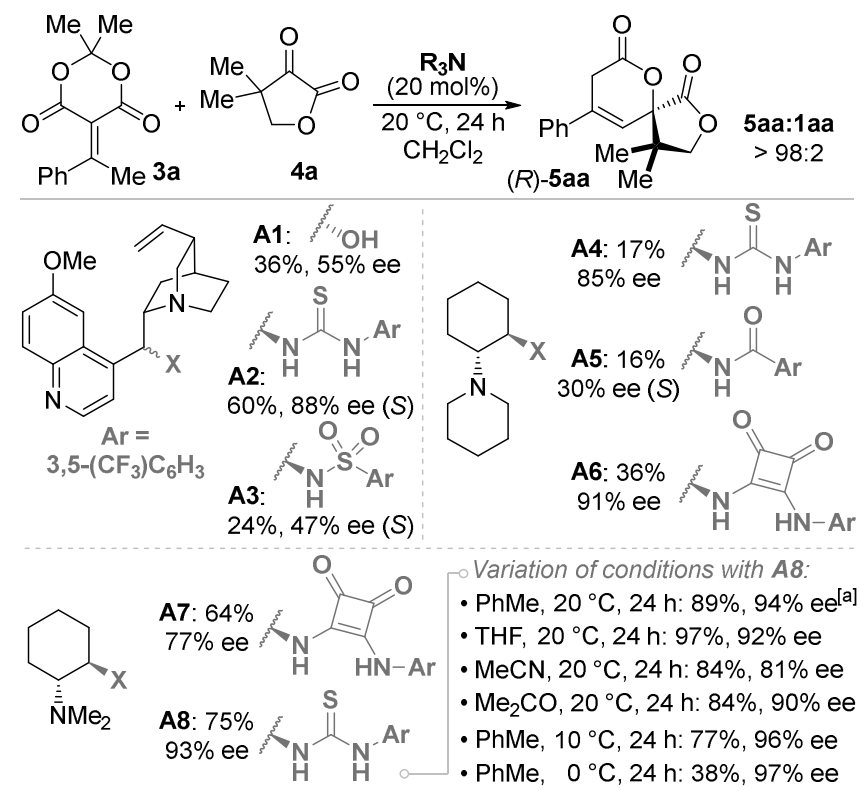

Scheme 3. Towards an enantioselective process. Reaction conditions: $3 \mathbf{a}(0.15 \mathrm{mmol})$, ketone $4 \mathbf{4 a}$ ( 1 equiv), catalyst $(20 \mathrm{~mol} \%)$ in the given solvent $(0.5 \mathrm{M})$ at $20^{\circ} \mathrm{C}$ for 24 hours. Percentage of isolated yield after column chromatography, enantiomeric excess (ee) determined by chiral HPLC and the ratio of isomers (5aa:1aa) was determined by ${ }^{1} \mathrm{H}$ NMR on the crude product. [a] 94:6 (5aa:1aa) was measured.

Various Cinchona-derived organocatalysts (see SI for full details) were first assessed for the transformation of the dihydro4,4-dimethyl-2,3-furandione 4a to 3,6-dihydropyran-2-ones 5aa (Scheme 3). The bifunctional thiourea organocatalyst $\mathbf{A 2}$ $(60 \%$ yield, $88 \%$ ee) proved to be more effective than the native quinine A1 $(36 \%$ yield, $55 \%$ ee and reverse enantioselectivity) or the sulfonamide derivatives A3 (24\%, $47 \%$ ee) both in terms of yields and ee. This marked outcome with regard to bifunctional-topology was also observed with organocatalysts A4-A6, having a cyclohexanediamine backbone, albeit lower yields were measured probably due to the sterically hindered piperidine moiety. Nevertheless, the squaramide derived catalyst A6 provided $\mathbf{9 1 \%}$ ee in $\mathbf{3 6 \%}$ yield. Importantly, in this series, the catalyst $\mathbf{A} 5$ having an amide functional group led to inverse enantioselectivity (30\% ee) in comparison to thiourea or squaramide analogues A4 and A6, showing the key importance of the hydrogen bonding donor moiety. To our delight, the less encumber catalysts A7-A8, having a dimethylamine moiety, furnished the 3,6-dihydropyran-2-ones 5aa with improved $64-75 \%$ yields and up to $93 \%$ ee for the original Takemoto catalyst A8. Interestingly, the catalysts A7-A8 possessing a $\mathrm{NMe}_{2} \mathrm{Brønsted} \mathrm{base} \mathrm{display} \mathrm{a}$ reverse influence of the $\mathrm{NH}$-hydrogen bonding donor part onto ee as the thiourea derivative $\mathbf{A} 8$ led to better ee than the squaramide $\mathbf{A 7}$ in the contrary to piperidine derivatives $\mathbf{A 4}$ and $\mathbf{A 6}$; then a subtle cooperation between the two functionalities of the catalyst is set for this new transformation (3a to 5aa). An optimization of reaction conditions with catalyst A8 showed that toluene furnished improved ee (94\%) and yields (89\%) albeit with the formation of a small amount of 5,6-dihydropyran-2-ones 1a. Nonetheless, the selectivity between isomers 5aa:1aa was in favor of the 3,6-dihydropyran2-ones 5aa (> 98/2 5aa:1aa) at $10^{\circ} \mathrm{C}$, obtained in $77 \%$ isolated yield and excellent $96 \%$ ee, while lower temperature $\left(0^{\circ} \mathrm{C}\right)$ led to a drop of yield (38\%). 
Table 1. Scope and limitations. ${ }^{[a]}$

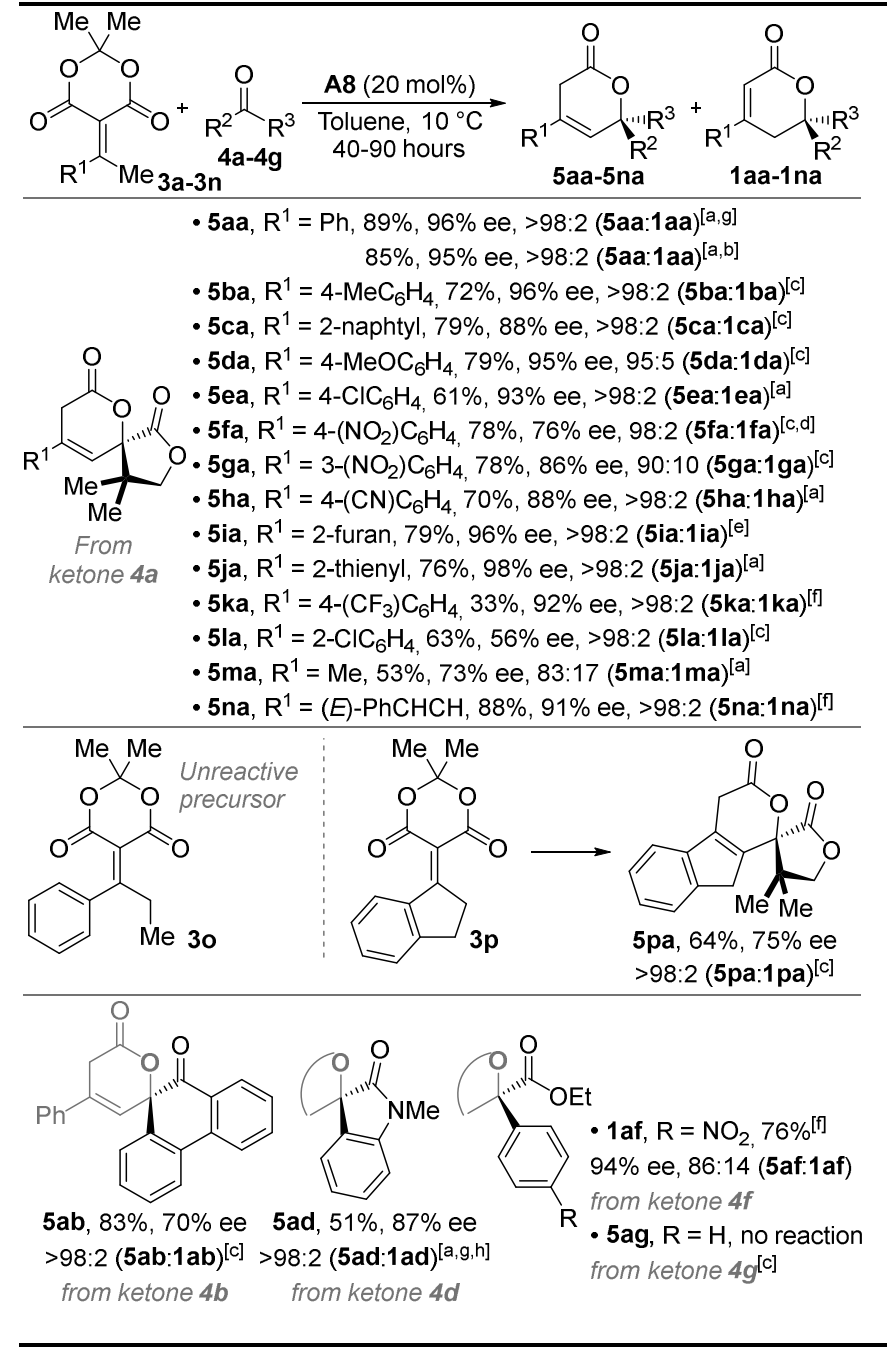

Reaction conditions: 3 ( $0.15 \mathrm{mmol})$, ketones 4 (1 equiv), catalyst $\mathbf{A} 8$ (20 mol\%) in $\mathrm{PhMe}(0.5 \mathrm{M})$ at $10^{\circ} \mathrm{C}$. Percentage of isolated yield of the pure major isomer 5 after column chromatography (unless otherwise noted), enantiomeric excess (ee) determined by chiral HPLC and the ratio of isomers (5:1) was determined by ${ }^{1} \mathrm{H}$ NMR on the crude product. [a] 40 hours of reaction. [b] On $1 \mathrm{mmol}$ scale. [c] 90 hours of reaction. [d] in $\mathrm{CH}_{2} \mathrm{Cl}_{2}$ for solubility issue. [e] At $20{ }^{\circ} \mathrm{C}$ in $\mathrm{CH}_{2} \mathrm{Cl}_{2}$ for 72 hours. [f] 72 hours of reaction. [g] The absolute configurations were determined by X-Ray diffraction for $(R)$-5aa and from similar structure in the literature for $(R)-5 \mathbf{a d}^{[6]}$ (see $\mathrm{SI}$ ); the absolute stereochemistry of the other products was drawn by analogy. [h] 1.3 equivalent of alkylidene Meldrum's acid $\mathbf{3 a}$ and catalyst $\mathbf{A} \mathbf{3}$ was used instead of $\mathbf{A} 8$ which gave $\mathbf{5 a b}$ in $74 \%$ yield and $55 \%$ ee (see $\mathrm{SI})$.

Having these conditions in hands, the substrate scope was addressed (Table 1). Increasing the reaction time to 40 hours allowed the formation of the expected product 5 aa in $89 \%$ yield while keeping an excellent enantiomeric excess of $96 \%$ ee, even on $1 \mathrm{mmol}$ scale (85\%, $95 \%$ ee). A series of alkylidene Meldrum's acid derivatives $\mathbf{3 b} \mathbf{b}-\mathbf{3} \mathbf{j}$ were engaged into a vinylogous transformation of dihydro-4,4-dimethyl-2,3-furandione $\mathbf{4 a}$ into 3,6-dihydropyran-2-ones $\mathbf{5 b a - 5 j a}$ as major products with yields between $61-79 \%$ and ees ranging from $76 \%$ to $98 \%$. The alkylidene Meldrum's acid flanked by a $4-$ $\mathrm{CF}_{3} \mathrm{C}_{6} \mathrm{H}_{4}$ moiety led to the corresponding 3,6-dihydropyran-2-ones $\mathbf{5 k a}$ with an excellent $92 \%$ ee but a moderate yield of $33 \%$ ( $42 \%$ of conversion). The conversion could be improved (> $90 \%$ of conversion) after $90 \mathrm{~h}$ of reaction but a lower ratio of 5ka:1 ka (74:26) was measured. In this series, product 5la obtained from the Meldrum's acid derivative $\mathbf{3}$, having a 2chlorophenyl moiety, proved to be more challenging (Table 1). Then, only $77 \%$ of conversion after 90 hours at $10^{\circ} \mathrm{C}$ was measured giving product $5 \mathrm{la}$ in moderate $63 \%$ isolated yield and $56 \%$ ee. In order to further probe the structure/activity relationship, one can consider that alkylidene Meldrum's acid flanked by two methyl group is still able to be involved into this aldol process, albeit lower reaction rate (67\% of conversion) and selectivity (5ma:1ma 83:17) was observed giving $5 \mathrm{ma}$ in $53 \%$ yield and $73 \%$ ee. On the other hand, the original product 5 na, having a versatile styrenyl group, was synthesized easily in $91 \%$ ee and $88 \%$ yield from the corresponding dienyl Meldrum's acid $\mathbf{4 n}$. Additionally, although more sterically hindered ethyl-derivative 30 proved to be unreactive, the cyclic-analogue, namely the indenyl-derived Meldrum's 
acid $3 p$, was transformed into the corresponding tetracyclic product 5 pa in $75 \%$ ee $(64 \%$ yield). Subsequently, we wondered whether this Meldrum's acid-based platform 3a could react with other ketones, known as good starting materials for the efficient enantioselective vinylogous synthesis of 5,6-dihydropyran-2-ones $\mathbf{1}^{[7],[8 \mathrm{a}-\mathrm{e}, 8 \mathrm{~g}-\mathrm{i}]}$ However, in our case, we expected to extend the chemical diversity with the formation of isomeric and non-racemic 3,6-dihydropyran-2-one architectures $\mathbf{5}$. Accordingly, the transformation of various ketones $\mathbf{4 b}, \mathbf{4 d}, \mathbf{4 f - g}$ proceeded with moderate to good yields $(50-83 \%)$ in favor of the major 3,6-dihydropyran-2-one products. However, the diketones $\mathbf{4} \mathbf{b}^{[8 \mathrm{e}]}$ and $\mathbf{4} \mathbf{d}^{[6]}$ were transformed into products $\mathbf{5 a b}$ and $\mathbf{5 a d}$ in only $70 \%$ and $55 \%$ ee respectively. To our delight, by means of epi-tosylamide quinine catalyst $\mathbf{A} \mathbf{3}$ instead of $\mathbf{A} 8$, the spiro-oxindole $\mathbf{5 a d}$ was obtained with improved $87 \%$ ee. In spite of the less activated phenyl $\alpha$-keto esters $\mathbf{4 g}$ did not react in these conditions, ${ }^{[8]}$ the more electrophilic para- $\mathrm{NO}_{2}$-phenyl $\alpha$-keto esters $\mathbf{4 f}$ furnished the corresponding dihydropyranones 5 af and 1 af as a 86:14 mixture of isomers as determined on the crude product. However, a complete isomerization of this mixture into the 5,6-dihydropyran-2-one product occurred during purification by silica gel column chromatography to afford 1 af in good $76 \%$ yield and $94 \%$ ee. ${ }^{[15]}$

On the basis of preliminary set of computations with trimethylamine as a model organocatalyst (see SI for full details), a proposed catalytic cycle is shown in Scheme 4. First, the deprotonation of alkylidene Meldrum's acid 3a gives the enolate 6a flanked by the $\mathrm{H}$-bonded tertiary ammonium $\left(\mathrm{R}_{3} \mathrm{NH}^{+}\right)$. Then, the addition to the ketone-electrophile 4 a gives the adduct 8aa (enantioselective step), though a transition state $\left(\mathrm{TS}_{6.8}=19.2 \mathrm{kcal} / \mathrm{mol}\right.$ ) showing a comgoplete proton-transfer from the ammonium to the alcohol-product 8aa. The subsequent cyclization leads to the ortho-ester 9aa along with a basepromoted proton migration. Importantly, it was found that the alternative (4+2) cycloaddition reaction (6a $+4 a$ to 9 aa) was more energetically demanding than the nucleophilic addition of dienolate $6 \mathbf{a}$ to $4 \mathbf{a}(24.9 \mathrm{vs} 19.2 \mathrm{kcal} / \mathrm{mol})$. The subsequent fragmentation process liberates a molecule of acetone to furnish the carboxylate 10aa. ${ }^{16]}$ Although the detail of the formal symmetry forbidden $1,3-\mathrm{H}$ shift was not easy to address from the computational point of view, it is believed that a C-C double bond isomerization occurs to reveal the hemi-malonate backbone of 11 aa. This $\mathrm{Csp}^{3}-\mathrm{CO}_{2}$ framework is then able to undergo a stepwise decarboxylation/tautomerization sequence $\left(\mathrm{TS}_{11-12}=-6.2 \mathrm{kcal} / \mathrm{mol}\right)$ to eventually deliver the kinetic product 5aa. Importantly, by means of a stronger base or longer reaction time an equilibration event occurs leading to the C-C double bond migration of 5aa to provide the more stable 5,6-dihydropyran-2-one 1aa having a conjugated alkene to the carbonyl functional group (via a formal protonation to $\mathrm{y}$-position).

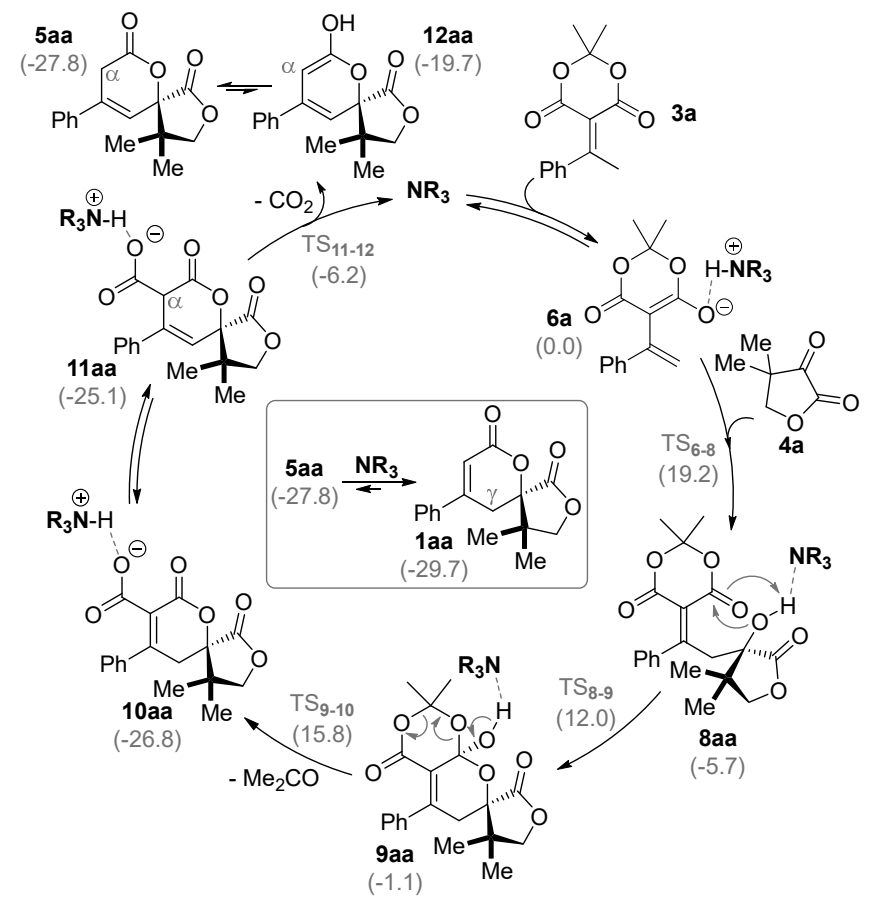

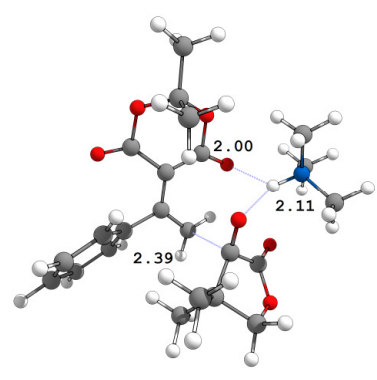

$\mathbf{T S}_{6-8}(19.2 \mathrm{kcal} / \mathrm{mol})$

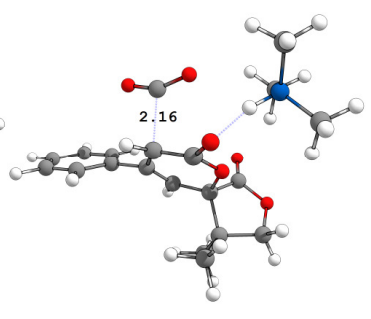

$\mathbf{T S}_{11-12}(-6.2 \mathrm{kcal} / \mathrm{mol})$ 
Scheme 4. Proposed mechanism based on DFT calculations. [a] The computed free energies $\left(\Delta G_{298}\right)$ of intermediates and transition states (TS) are given in $\mathrm{kcal} / \mathrm{mol}$ in brackets with $\mathrm{Me}_{3} \mathrm{~N}$ as catalyst (selected distances in $\AA$ ).

In conclusion, we have shown that ketone derived alkylidene Meldrum's acids $\mathbf{3}$ are novel C4-synthon capable of being engage into a vinylogous formal $(4+2)$ cycloaddition reaction with reactive ketones to furnish an unprecedented route to 3,6-dihydropyran-2-ones 5 upon Brønsted base catalytic conditions. By means of the commercially available bifunctional Takemoto organocatalyst up to $98 \%$ ee were obtained, especially for original spiro compound 3,6-dihydropyran-2-ones 5 . The exploitation of this novel and readily available vinylogous platform in enantioselective transformations and the use of original products obtained thereby is currently under investigation.

\section{Acknowledgements}

We are grateful to the Charm3At-SynOrg Interlabex for a post-doctoral fellowship to S. Wittmann, the CNRS (UMR 8182) and the University Paris Saclay for financial supports. We also thank Emilie Kolodziej for technical assistance with the HPLC analysis. This work has been partially supported by INSA Rouen Normandy, University of Rouen Normandy, the Centre National de la Recherche Scientifique (CNRS), EFRD, and Labex SynOrg (ANR-11-LABX-0029), and by Region Normandie (CRUNCh network). VG thanks Ecole Polytechnique and the CINES (project A0070810977) for computational resources.

Keywords: asymmetric synthesis • dihydropyranones $\bullet$ Meldrum's acid • organocatalysis $\bullet$ vinylogy

[1] R. C. Fuson, Chem. Rev. 1935, 16, 1-27.

[2] For leading reviews on indirect-vinylogous catalytic processes, see: (a) S. E. Denmark, J. R. Heemstra Jr., G. L. Beutner, Angew. Chem. Int. Ed. 2005, 44, 4682-4698; (b) G. Casiraghi, L. Battistini, C. Curti, G. Rassu, F. Zanardi, Chem. Rev. 2011, 111, 3076-3154.

[3] For selected reviews on direct-vinylogous aldol-processes, see: (a) S. V. Pansare, E. K. Paul, Chem. Eur. J. 2011, 17, 8770-8779; (b) V. Bisai, Synthesis 2012, 44, 1453-1463; (c) I. D. Jurberg, I. Chatterjee, R. Tannert, P. Melchiorre, Chem. Commun. 2013, 49, 4869-4883; (d) X.-Y. Chen, Q. Liu, P. Chauhan, D. Enders, Angew. Chem. Int. Ed. 2018, 57, 3862-3873; (e) R. Dalpozzo, R. Mancuso, Synthesis 2018, 50, 24632472; (f) H. Li, L. Yin, Tetrahedron Lett. 2018, 59, 4121-4135.

[4] (a) T. B. Poulsen, C. Alemparte, K. A. Jørgensen, J. Am. Chem. Soc. 2005, 127, 11614-11615; (b) D. Xue, Y.-C. Chen, Q.-W. Wang, L.-F. Cun, J. Zhu, J.-G. Deng, Org. Lett. 2005, 7, 5293-5296; (c) A. J. Grenning, Synlett 2017, 28, 633-639.

[5] (a) P. S. Tiseni, R. Peters, Angew. Chem. Int. Ed. 2007, 46, 5325-5328; (b) P. S. Tiseni, R. Peters, Org. Lett. 2008, 10, 2019-2022; (c) P. S. Tiseni, R. Peters, Chem. Eur. J. 2010, 16, 2503-2517.

[6] L.-T. Shen, P.-L. Shao, S. Ye, Adv. Synth. Catal. 2011, 353, 1943-1948.

[7] For selected examples of NHC organocatalyzed enantioselective syntheses of 5,6-dihydropyran-2-one, see: (a) J. Mo, X. Chen, Y. R. Chi, J. Am. Chem. Soc. 2012, 134, 8810-8813; (b) Z. Xiao, C. Yu, T. Li, X.-S. Wang, C. Yao, Org. Lett. 2014, 16, 3632-3635; (c) Y. Lin, L. Yang, Y. Deng, G. Zhong, Chem. Commun. 2015, 51, 8330-8333; (d) Y. Que, T. Li, C. Yu, X.-S. Wang, C. Yao, J. Org. Chem. 2015, 80, 3289-3294; (e) X. Rong, H. Yao, W. Xia, Y. Du, Y. Zhou, H. Liu, ACS Combinatorial Science 2016, 18, 220-224; (f) J. Yan, K. Shi, C. Zhao, L. Ding, S. Jiang, L. Yang, G. Zhong, Chem. Commun. 2018, 54, 1567-1570.

[8] For selected examples of Brønsted base organocatalyzed enantioselective syntheses of 5,6-dihydropyran-2-one, see: (a) C. Cassani, P. Melchiorre, Org. Lett. 2012, 14, 5590-5593; (b) T.-P. Gao, J.-B. Lin, X.-Q. Hu, P.-F. Xu, Chem. Commun. 2014, 50, 8934-8936; (c) T.-Z. Li, Y. Jiang, Y.-Q. Guan, F. Sha, X.-Y. Wu, Chem. Commun. 2014, 50, 10790-10792; (d) J.-L. Han, C.-H. Chang, Chem. Commun. 2016, 52, 23222325; (e) Y. Jiang, J.-H. Fu, T.-Z. Li, F. Sha, X.-Y. Wu, Org. Biomol. Chem. 2016, 14, 6435-6441; (f) T.-P. Gao, D. Liu, J.-B. Lin, X.-Q. Hu, Z.Y. Wang, P.-F. Xu, Org. Chem. Front. 2016, 3, 598-602; (g) J.-L. Han, Y.-D. Tsai, C.-H. Chang, Adv. Synth. Catal. 2017, 359, 4043-4049; (h) S. Crotti, N. Di lorio, A. Mazzanti, P. Righi, G. Bencivenni, J. Org. Chem. 2018, 83, 12440-12448; (i) Z.-G. Zhang, J.-H. Fu, F. Sha, X.-Y. Wu, Tetrahedron 2018, 74, 3557-3563.

[9] E. Chupakhin, O. Babich, A. Prosekov, L. Asyakina, M. Krasavin, Molecules 2019, 24, 4165.

[10] G. Baxter, R. Brown, Aust. J. Chem. 1975, 28, 1551-1557.

[11] For reviews on catalytic transformations of Meldrum's acid derivatives, see: (a) A. M. Dumas, E. Fillion, Acc. Chem. Res. 2010, 43, 440-454; (b) E. Pair, T. Cadart, V. Levacher, J.-F. Brière, ChemCatChem 2016, 8, 1882-1890.

[12] For pioneering dimerization of alkylidene Meldrum's acids and discussion of their acidity, see: (a) J. Leitich, P. Schuster, A. Eitel, Tetrahedron 1967, 23, 2221-2227; (b) P. Schuster, A. Stephen, O. E. Polansky, F. Wessely, Monatsh. Chem. 1968, 99, 1246-1276; (c) R. Akué-Gédu, H. El-Hafidi, B. Rigo, D. Couturier, J. Heterocyclic Chem. 2006, 43, 365-369.

[13] The presence of this substructure was reported into a naturally occurring product with an inhibitory activitie against ubiquitin-specific protease 7: N. Tanokashira, S. Kukita, H. Kato, T. Nehira, E. D. Angkouw, R. E. P. Mangindaan, N. J. de Voogd, S. Tsukamoto, Tetrahedron 2016, 72, $5530-5540$

[14] CCDC 1998088, 1998089 and 1992496 contain the supplementary crystallographic data for compound (+/-)-1aa, (+/-)-5aa and (R)-5aa.

[15] The vinylogous addition of 3 a successfully took place to acyclic trifluoroacetophenone (67\% yield and $93 \%$ ee) and para-CN-phenyl a-keto ethylester $(50 \%$ yield and $82 \%$ ee) but led to the corresponding 5,6-dihydropyran-2-ones 1 due to an isomerization event for a prolonged reaction time and purification on silica gel column chromatography.

[16] In the presence of tetramethylguanidine, an intermediate like 10aa, as a guanidinium carboxylate salt, precipitated out of the solution to provide a crystal suited for X-Ray diffraction analysis (see SI). 